\title{
Correspondence
}

Letters to the Editor should not exceed 500 words.

Influenza and Respiratory Failure

G. R. Gerson, F.F.A.R.C.s.; D. G. Price, F.F.A.R.C.S., and J. C. Symons, M.B. ........233

Rectal Cancer from Axle Grease?

O. A. A. Bock, D.M., and others .............233

Death of Doctors

D. M. Wallace, F.R.C.s.

Management of Deep Vein Thrombosis

A. J. Handley, M.R.C.P. .................234

Intraocular Lenses

P. D. Trevor-Roper, F.R.C.S.

Respiratory Failure in Chest Wall Injuries

R. E. Loder, F.F.A.R.C.S......................234

Wigs and Waste

Anne E. McCandless, M.D...................2235

Minnitt and the End of an Era

T. C. Gray, F.F.A.R.C.S....................235

The Experience of Time

S. Krauss, M.D..
Pulmonary Sensitivity to Nitrofurantoin

Susan Evans, M.B.,; and B. A. Juby, M.R.c.s. 235

Septic Shock

M. Ridley, M.R.c.Path., and others; E. N.

Wardle, M.R.C.P.; and W. Ellis, F.R.C.S.I...2236

Spinal Board for Road Casualties

K. C. Easton, M.B.......................236 Facial Pain

J. F. Bates, D.D.S., Kathleen Powell, B.D.s.; and H. L. Winter, M.D....................2237

Ovulation after the Pill

H. P. Dunn, F.R.C.o.G.

Oral Contraceptives and Depression

J. Braham, M.D. .....................

Whooping-cough Immunization

G. W. J. Bousfield, M.D..

Unusual Effect of Fenfluramine

D. N. Golding, M.D.; and D. V. Hawks,

PH.D. .................................... 238
Cost of Medical Publications

P. A. Warren .......................... 238

Mental Illness and the Family Doctor

S. Bourne, M.R.C.P., D.P.M.................238

Postoperative Fibrinolysis

R. H. Whittaker, F.R.C.S., and others........238

Psychiatric Drugs Left at Home

A. A. Robin, M.D., and D. L. Freeman-

Browne, A.A.P.s.w. ......................... 239

Hospital Staffing Structure

G. A. Medhurst, M.R.C.S., P. S. Andrews, M.D.; and J. J. Shipman, F.R.c.S. .......... 239

General Practitioners and the District Hospitals

S. A. P. Jenkins, M.B......................240

Private Medical Insurance

J. A. Hersey, M.R.c.s.; and E. V. Bevan,

M.D. ................................. 240

Vocational Training for General Practice

G. Scott, M.D..............................240
SIR,-In his article on influenza and respiratory failure (10 January, p. 97) Dr. J. C. Stoddart mentions the need for artificial ventilation of patients with respiratory failure following influenza and respiratory tract infection. In the intensive therapy unit of the Royal Sussex County Hospital during the current influenza epidemic commencing in early December it has proved necessary to ventilate artificially six patients who were suffering from respiratory tract infection associated with influenza.

The ages of these patients ranged from 30 to 65 . Four of them had no previous history of chest disease, and of the two others one suffered from chronic bronchitis and the other was an old poliomyelitis victim with weak respiratory musculature. The indications for intermittent positive pressure ventilation were in all cases progressive hypoxaemia combined with exhaustion. In only two cases was there associated respiratory acidosis as evidenced by an increased $\mathrm{PCO}_{2}$, one of these being the chronic bronchitic patient. The length of time the six patients were ventilated via an oral cuffed Portex endotracheal tube varied from 37 to 94 hours. Four of the patients had tracheostomies following their periods of endotracheal intubation, and were then ventilated for periods of up to 10 days. Two of them are being weaned off their ventilators at present. All of the patients were given either phenoperidine or Omnopon, as necessary, during the time they were being ventilated via the oral endotracheal tubes to facilitate adequate artificial ventilation and provide freedom from distress. Two of the six patients died

\section{Rectal Cancer from Axle Grease?}

SIR,-Your leading article entitled patient in whom mineral oil may be related "Cancer from Mineral Oil" ( 22 November, to a carcinoma of the rectum. We propose p. 443) prompts us to relate the history of a to report the details of the case later.
The patient, a 36-year-old coloured male, presented with a six-year history of intermittent rectal bleeding. On rectal examination an irregular lesion, which appeared to encircle the rectum, was felt at the tip of the finger. This was confirmed at proctoscopy, and, because the macroscopic appearances of the lesion were somewhat unusual, several biopsies were taken. Sigmoidoscopy with a children's instrument and barium enema examination revealed no other lesion. In two biopsies the changes were those of chronic inflammation, but in the third the appearances were those of a well-differentiated infiltrating adenocarcinoma.

Abdomino-perineal excision was performed. There were no visible secondary deposits in the liver or peritoneum. In the opened specimen the lesion consisted of a series of irregular ridges lying side by side but tending to fan out more proximally. Histological examination revealed a superficial infiltrating well-differentiated adenocarcinoma arising in an area of organized granulation tissue, which disturbed the normal architecture of the rectum.

Because the lesion was so unusual and because the patient was serving his second term of imprisonment, it was thought that further inquiry might reveal some connexion between his long stay in gaol and the carcinoma. It is known that prisoners often hide a variety of articles in their rectum. The patient related that he had had a prolapsed rectum as a child. As a young man he had on occasions passed blood with his motions. He was first sentenced in August 1955. At that time prisoners were apparently not allowed to have tobacco with them. Because he usually worked in gangs breaking stones, the opportunity often arose to obtain tobacco from passers-by. This was carefully wrapped in paper-usually torn-up cement bags-and then inserted into the rectum, the passage of the wrapped tobacco being facilitated by grease obtained from wheel-barrow axles. In the quiet of the evening the rectum was emptied and the unharmed tobacco recovered. He was unable to estimate how many times a week he hid tobacco in this way. 